\title{
Functional characterization of the AGL1 aegerolysin in the mycoparasitic fungus Trichoderma atroviride reveals a role in conidiation and antagonism
}

\author{
Mukesh Dubey $^{1}$ [D Dan Funck Jensen ${ }^{1} \cdot$ Magnus Karlsson ${ }^{1}$
}

Received: 7 May 2020 / Accepted: 29 September 2020 / Published online: 14 October 2020

(c) The Author(s) 2020

\begin{abstract}
Aegerolysins are small secreted pore-forming proteins that are found in both prokaryotes and eukaryotes. The role of aegerolysins in sporulation, fruit body formation, and in lysis of cellular membrane is suggested in fungi. The aim of the present study was to characterize the biological function of the aegerolysin gene agll in the mycoparasitic fungus Trichoderma atroviride, used for biological control of plant diseases. Gene expression analysis showed higher expression of agll during conidiation and during growth in medium supplemented with cell wall material from the plant pathogenic fungus Rhizoctonia solani as the sole carbon source. Expression of agll was supressed under iron-limiting condition, while agll transcript was not detected during T. atroviride interactions with the prey fungi Botrytis cinerea or $R$. solani. Phenotypic analysis of agll deletion strains ( $\triangle a g l l$ ) showed reduced conidiation compared to $T$. atroviride wild type, thus suggesting the involvement of AGL1 in conidiation. Furthermore, the $\Delta a g l l$ strains display reduced antagonism towards $B$. cinerea and $R$. solani based on a secretion assay, although no difference was detected during direct interactions. These data demonstrate the role of AGL1 in conidiation and antagonism in the mycoparasitic fungus T. atroviride.
\end{abstract}

Keywords Aegerolysin $\cdot$ Antagonism $\cdot$ Haemolysin $\cdot$ Mycoparasitism $\cdot$ Pore-forming proteins $\cdot$ Trichoderma

\section{Introduction}

The aim of this study was to characterize the biological function of an aegerolysin protein in the fungus Trichoderma atroviride, used for biological control of plant pathogenic fungi in agriculture, with emphasis on its role in asexual development and interactions with other fungi. Aegerolysin (Pfam 06355, InterPro IPR009413) is a family of lipid-binding proteins that are found in both prokaryotes and eukaryotes (Novak et al. 2015; Butala et al. 2017). Aegerolysin

Communicated by Stefan Hohmann.

Electronic supplementary material The online version of this article (https://doi.org/10.1007/s00438-020-01732-3) contains supplementary material, which is available to authorized users.

Mukesh Dubey

mukesh.dubey@slu.se

1 Department of Forest Mycology and Plant Pathology, Uppsala Biocenter, Swedish University of Agricultural Sciences, P.O. Box 7026, 75007 Uppsala, Sweden family proteins are typically small $(15-20 \mathrm{kDa})$ with low isoelectric point, a predicted $\beta$-structure and are shown to be active in a broad $\mathrm{pH}$ range from 3.5 to 10.5 (Novak et al. 2015; Butala et al. 2017). In fungi, aegerolysins are reported from many species with varying lifestyles and ecological niches; however, functional characterization is only reported from a few species. In the basidiomycete fungi Agrocybe aegerita, A. cylindracea, Pleurotus ostreatus, and P. eryngii, expressions of aegerolysin genes are up-regulated during sexual development, specifically during the development of young fruiting bodies (primordia) and in the basidiospores (Fernandez Espinar and Labarère 1997; Berne et al. 2002; Lee et al. 2002; Shim et al. 2006; Joh et al. 2007). Likewise, the expressions of aegerolysin genes are induced during asexual development, in the conidiophore and conidia of the ascomycetes Alternaria gaisen and Aspergillus ory$z a e$, respectively (Bando et al. 2011; Roberts et al. 2011). Higher expressions of aegerolysin genes are also recorded during spore germination and hyphal growth of A. fumigatus, A. terreus, and A. niger (Wartenberg et al. 2011; Nayak et al. 2012, 2019). However, deletions of the aegerolysin genes nigAl and nigA2 in the plant pathogen A. niger do not 
affect growth, sporulation, or virulence in the corresponding mutants, suggesting functional redundancy (Novak et al. 2019). In addition, expressions of nigAl and nigA2 are shown to be up-regulated by nutrient source (carbon and nitrogen), abiotic stress (temperature and $\mathrm{pH}$ ), oxidative stress $\left(\mathrm{H}_{2} \mathrm{O}_{2}\right)$, and anaerobic stress (Novak et al. 2019).

Aegerolysin family proteins are haemolytic and cytolytic to mammalian cell lines and insect cells (Butala et al. 2017; Panevska et al. 2019). To exert cytolysis, certain aegerolysins interact with the cellular membrane in their monomeric form; for example, AspHS from A. fumigatus. While others, for example ostreolysin A (OlyA), pleurotolysin A2 (PlyA2), and erylysin A (EryA) from P. ostreatus, function in their heterodimeric form in combination with other proteins carrying the membrane attack complex/perforin domain, such as pleurotolysin B (PlyB) and erylysin B (EryB) (Tomita et al. 2004; Shibata et al. 2010; Gilbert et al. 2013; Ota et al. 2013; Panevska et al. 2019).

The aegerolysin protein asp-haemolysin (AspHS) from the human pathogen A. fumigatus is shown to lyse mammalian cell lines, consequently decreasing the viability of macrophages and human vascular endothelial cells (Kumagai et al. 1999, 2001) and thereby contributing to A. fumigatus virulence. However, functional characterization of AspHS by genetic transformation results in no significant difference in virulence between the wild type (WT) and the aspHS deletion mutant, suggesting functional redundancy of the AspHS aegerolysin in A. fumigatus. Furthermore, purified aegerolysins (OlyA, PlyA2, and EryA) from $P$. ostreatus exhibited toxicity towards western corn rootworm larvae and adults and Colorado potato beetle larvae by enhancing the permeability of the insect cell membrane (Panevska et al. 2019). The toxic effect of aegerolysins is a result of their interactions with cell membrane lipids that induce the formation of trans-membrane pores and lead to the disruption of membrane permeability and osmotic lysis (Nayak et al. 2011, 2015; Butala et al. 2017; Panevska et al. 2019).

Trichoderma atroviride is a filamentous ascomycete fungus that can parasitize and kill several plant pathogenic fungi (mycoparasitism), and certain strains are therefore used commercially as biological control agents against plant pathogenic fungi in agricultural and horticultural production systems (Druzhinina et al. 2011). T. atroviride produces hydrolytic enzymes and secondary metabolites as part of the mycoparasitic attack on the fungal prey (Druzhinina et al. 2011; Mukherjee et al. 2012).

In the current study, we identified a single aegerolysin gene (agll) in the T. atroviride genome. Our results showed an induced expression of agll in conidiating mycelia, and during hyphal growth on medium supplemented with cell wall material from the plant pathogenic fungus Rhizoctonia solani. By generating agll deletion mutants, we demonstrated a role for AGL1 in conidial development and antagonism in $T$. atroviride.

\section{Materials and methods}

\section{Gene identification, sequence analysis, and phylogenetic analysis}

Genome sequences of 100 fungal species were screened for the presence of aegerolysin genes by BLASTP analysis using amino acid sequences of characterized aegerolysins from the ascomycetes A. fumigatus (GenBank accession number: EAL86341) and A. terreus (EAU36830), and the basidiomycetes A. aegerita (AAC02265), P. eryngii (BAN83907), and $P$. ostreatus (AAX21097). The presence of signal peptides and conserved domains were analysed using the Simple Modular Architecture Research Tool (SMART) (Bork et al. 2009) and Conserved Domain Search (CDS) (MarchlerBauer et al. 2011). SecretomeP 2.0 (Bendtsen et al. 2004) was used to search for non-classical secretion signals.

Alignment of aegerolysin amino acid sequences was done using Muscle (Edgar 2004) and phylogenetic analysis was performed using maximum-likelihood methods implemented in MEGA X ver. 10 (Kumar et al. 2018). The WAG (Whelan and Goldman) with $\mathrm{G}$ (Gamma distribution) amino acid substitution model (Whelan and Goldman 2001) was used and pairwise deletion of gaps. Statistical support for branches was assessed by 1000 -iteration bootstrap resampling.

\section{Fungal strains and culture conditions}

T. atroviride strain IMI206040 (WT) and mutants derived from it, Botrytis cinerea strain B05.10 and R. solani strain SA1 were maintained on potato dextrose agar (PDA; Oxoid, Cambridge, UK) medium at $25{ }^{\circ} \mathrm{C}$. Synthetic minimal salt (SMS) liquid medium (Dubey et al. 2012) supplemented with $1 \%$ glucose was used for submerged liquid culture unless otherwise specified. Culture medium for different nutrient conditions was prepared by substituting $1 \%$ glucose in SMS medium with colloidal chitin $(1 \%), R$. solani cell wall material (RsCW) (1\%), or $N$-acetylglucosamine (NAG; Sigma-Aldrich, St. Louis, MO, USA) (10 mM). Limitation media for carbon (C lim), nitrogen ( $\mathrm{N} \mathrm{lim})$, and carbon + nitrogen $(\mathrm{C}+\mathrm{N}$ lim $)$ were prepared as described before (Dubey et al. 2012). Starvation for iron (Fe lim) was induced by a tenfold reduction of $\mathrm{FeSO}_{4} \times 7 \mathrm{H}_{2} \mathrm{O}$ concentration in SMS medium. Colloidal chitin was prepared from crab-shell chitin (Sigma-Aldrich, St. Louis, MO, USA) as described previously (Roberts and Selitrennikoff 1988). $R$. solani cell wall material was prepared as described previously (Inglis and Kawchuk 2002). 


\section{Gene expression analysis}

Gene expression analysis of agll in T. atroviride was performed during growth in liquid media supplemented with different nutrients or stress agents, during mycoparasitic fungal-fungal interactions with $B$. cinerea and $R$. solani, and during different developmental stages.

For gene expression analysis in different nutritional conditions, T. atroviride mycelium was cultivated in $50 \mathrm{ml}$ SMS medium with $1 \%$ glucose in flasks (Dubey et al. 2012), and harvested by filtering through Miracloth, washed with sterile distilled water, and transferred to new flasks containing $50 \mathrm{ml}$ of fresh SMS medium containing different nutrient regimes. T. atroviride cultivated in SMS with $1 \%$ glucose was used as control treatment. Mycelia were harvested $24 \mathrm{~h}$ post-inoculation (hpi), washed in distilled sterile water, frozen in liquid nitrogen, and stored at $-70^{\circ} \mathrm{C}$.

For gene expression analysis during interactions, an in vitro dual culture plate confrontation assay was used (Dubey et al. 2012). A $3 \mathrm{~mm}$-diameter agar plug cut from the growing front of $T$. atroviride and B. cinerea or $R$. solani mycelia was inoculated on opposite sides of a $9 \mathrm{~cm}$-diameter PDA plate, covered with a cellophane membrane to facilitate harvesting of the mycelium. The mycelial front $(7-10 \mathrm{~mm})$ of $T$. atroviride from the interaction zone was harvested $24 \mathrm{~h}$ after contact and immediately frozen in liquid nitrogen and stored at $-70{ }^{\circ} \mathrm{C}$. T. atroviride confronted with itself was used as control treatment.

For gene expression analysis during different developmental stages, a $3 \mathrm{~mm}$-diameter agar plug from the growing mycelial front of $T$. atroviride was transferred to PDA plates covered with a cellophane membrane. Experimental plates were incubated in darkness, except for a daily $30 \mathrm{~min}$ light treatment to induce conidiation. Mycelia were harvested
2 days post-inoculation (dpi) representing vegetative mycelial growth stage (VM), at 3 dpi representing the early stage of conidiating mycelium (ECM) and at 5 dpi representing conidiated mycelium (CM).

RNA extraction was done using the Qiagen RNeasy kit following the manufacturer's protocol (Qiagen, Hilden, Germany). One microgram of total RNA was reverse transcribed (RT) in a total volume of $20 \mu \mathrm{l}$ using the Maxima first strand cDNA synthesis kit (Fermentas, St. Leon-Rot, Germany). Transcript levels were estimated by quantitative PCR (qPCR) using the SYBR Green PCR Master Mix (Fermentas, St. Leon-Rot, Germany) in an iQ5 qPCR System (Bio-Rad, Hercules, CA, USA) as described previously (Dubey et al. 2012). Melt curve analysis was performed after the qPCR reactions, to confirm that the signal was the result of a single product amplification. Relative expression levels for $T$. atroviride target genes in relation to actl and sarl (Brunner et al. 2008) expression were calculated from the $\mathrm{Ct}$ values and the primer amplification efficiencies by using the formula described by Pfaffl (2001). Gene expression analysis was carried out in four biological replicates, each based on two technical replicates. Primer sequences used for gene expression analysis are given in Table 1.

\section{Construction of gene deletion cassette}

Genomic DNA from $T$. atroviride was extracted using hexadecyl-tri-methyl-ammonium bromide (CTAB) method (Nygren et al. 2008). Phusion DNA polymerase (Finnzymes, Vantaa, Finland) was used for PCR amplification (Dubey et al. 2012) of $\sim 1 \mathrm{~kb} 5$ '-flank and 3'-flank regions of the agll gene from genomic DNA of $T$. atroviride using primer pairs AL_ups F/AL_ups R and AL_ds F AL_ds R, respectively (Table 1). Gateway entry clones of the purified 5'-flank and
Table 1 List of primers used in this study

\begin{tabular}{|c|c|c|}
\hline Name & Target/purpose & Sequences $\left(5^{\prime} \rightarrow 3^{\prime}\right)$ \\
\hline AL F & agl1 & tcaaaaacgccgectatca \\
\hline AL R & & cctgacgccgcacctgag \\
\hline Actin F & actl & ctcacatccttcgccaatcactc \\
\hline Actin R & & agcccagctgccatacacaag \\
\hline Sar1 F & sarl & ggtgatgcgacagggctacg \\
\hline Sar1 R & & tgtcatcaccgggagccacta \\
\hline AL_ups F & agll upstream & ggggacaactttgtatagaaaagttggccgcattgcctagacttgtt ${ }^{\mathrm{a}}$ \\
\hline AL_ups R & & ggggactgcttttttgtacaaacttgatggcaagggtaatgggtat ${ }^{\mathrm{a}}$ \\
\hline AL_ds F & agll downstream & ggggacagctttcttgtacaaagtggttgggagtgcgagaaaagagg \\
\hline AL_ds R & & ggggacaactttgtataataaagttggcattgcagagcgattggtt ${ }^{\mathrm{a}}$ \\
\hline Hyg F & hygB cassette & gcgegcaattaaccetcac \\
\hline Hyg R & & gaattgcgcgtacagaactcc \\
\hline AL_ko F & Mutant validation & ctggaggcgccagagatta \\
\hline AL_ko R & & gacgtagcccgggttgaaa \\
\hline
\end{tabular}

${ }^{\mathrm{a}}$ attB and attBr sequences are underlined 
3'-flank PCR fragments were generated as described by the manufacturer (Invitrogen, Carlsbad, CA, USA). The gateway entry clone for the hygromycin cassette (hygB), constructed during our previous studies (Dubey et al. 2020), was used. The gateway LR recombination reaction was performed using entry plasmid of respective fragments and the destination vector pPm43GW (Karimi et al. 2005) to generate the deletion vectors following the conditions described by the manufacturer (Invitrogen, Carlsbad, CA, USA).

\section{Agrobacterium tumefaciens-mediated transformation and validation of transformants}

The deletion vector was transformed into Agrobacterium tumefaciens strain AGL1 based on a previous protocol for T. harzianum (Utermark and Karlovsky 2008). Transformed strains were selected on plates containing $100 \mu \mathrm{g} /$ $\mathrm{ml}$ of hygromycin (Sigma-Aldrich, St. Louis, MO, USA). Validation of homologous integration of the deletion cassettes in putative transformants was performed using a PCR screening approach with primer combinations targeting the hygB cassette (Hyg F/Hyg R) and sequences flanking the deletion cassettes (AL_ko F/AL_ko R) as described previously (Dubey et al. 2020). PCR-positive transformants were repeatedly sub-cultured on PDA plates without the selectable agent five times, followed by re-exposure to selection antibiotics to test for mitotic stability. Two rounds of single spore purification were performed to purify mitotically stable colonies as described previously (Dubey et al. 2012). Expression of agll in the WT and the gene deletion strains was determined by RT-PCR analysis using RevertAid premium reverse transcriptase (Fermentas, St. LeonRot, Germany) and primer pairs specific for agll (AL F/AL R) (Table 1). Three independent $T$. atroviride agll deletion strains $(\Delta \mathrm{A}, \Delta a g l l \mathrm{~B}$, and $\Delta a g l l \mathrm{C})$ along with the WT were used in phenotype analyses.agll

\section{Phenotypic analyses}

A $3 \mathrm{~mm}$-diameter agar plug from the growing mycelial front of $T$. atroviride strains was transferred to solid agar and colony morphology and growth diameter were recorded every day. Conidia were harvested from a 10 day old plate in $10 \mathrm{ml}$ distilled water and filtered through Miracloth to remove the mycelial debris. Conidial concentration was determined under the microscope using a bright-line haemocytometer (Sigma-Aldrich, St. Louis, MO, USA). Each experiment had three biological replicates and was repeated two times.

\section{Antagonism tests}

Antagonistic behaviour of $T$. atroviride WT and mutants against $B$. cinerea and $R$. solani was tested using an in vitro plate confrontation assay on PDA medium as described previously (Dubey et al. 2012). The growth of B. cinerea and $R$. solani was measured daily until their mycelial front reached the $T$. atroviride mycelial front, while the growth of T. atroviride strains was measured until the fungus reached the opposite side in the plate.

The role of secreted factors in antagonism was assayed by growing $T$. atroviride WT and mutant strains on PDA, covered with cellophane, at $25{ }^{\circ} \mathrm{C}$. T. atroviride colonies were injured with a scalpel and exposed to light to induce conidiation (Hernández-Oñate et al. 2012). The cellophane was removed when $T$. atroviride covered the plates, followed by inoculation with $B$. cinerea or $R$. solani agar plugs. PDA plates that were not previously inoculated with $T$. atroviride strains were used as control. Linear growth of $B$. cinerea or $R$. solani was recorded 3 dpi. The experiment was performed in three biological replicates.

\section{Statistical analysis}

Analysis of variance (ANOVA) was performed on gene expression and phenotype data using a General Linear Model approach implemented in Statistica version 13 (StatSoft, Tulsa, OK, USA). Pairwise comparisons were made using the Fisher's or Tukey-Kramer methods at the 95\% significance level.

\section{Results}

\section{Identification and distribution of aegerolysin genes in Sordariomycota}

Out of 100 analysed fungal genomes, representing 35 sordariomycete species, aegerolysin genes were identified in 26 genomes, representing 15 different species (Table S1). Analysis of 19 Trichoderma strains revealed that T. asperellum CBS 433.97, T. virens Gv29-8, and T. atroviride IMI 206040 contained one aegerolysin gene each (Table S1). Genome analysis of 12 strains representing six species with mycoparasitic behaviour from the genus Clonostachys showed the presence of one aegerolysin gene in all analysed genomes except for Clonostachys solani 1703 and C. chloroleuca CBS 570.77 that contained two genes each (Table S1). Among plant pathogenic Fusaria, a single aegerolysin gene was found in a single strain, $F$. oxysporum $\mathrm{f}$. sp. conglutinans race 254008 (PHW808), among 15 different strains representing five species. No aegerolysin genes were identified in 11 different species of plant pathogenic Colletotrichum (Table S1). All investigated entomopathogenic species (Beauveria, Cordyceps, Metarhizium, and Tolypocladium) contained a single aegerolysin gene (Table S1). 


\section{Sequence analysis of a predicted aegerolysin in Trichoderma atroviride}

The identified aegerolysin gene in T. atroviride (protein ID: 32864) was 503 bp long with a 62 bp intron and named agll (GenBank accession number: EHK42428.1). It was predicted to encode a polypeptide composed of 146 amino acids with a molecular weight of $15.98 \mathrm{kDa}$ and an estimated isoelectric point at $\mathrm{pH}$ 6.72. SMART analysis predicted that AGL1 contained an aegerolysin domain (Pfam PF06355, InterPro IPR009413) between amino acid positions 8-140. This structure was further verified by CDS. No N-terminal secretion signal peptide was identified using SignalP. However, SecretomeP analysis predicted the secretion of AGL1 (score 0.87) through a non-classical secretion pathway. Sequence alignments of the predicted aegerolysin proteins from the three Trichoderma species showed 66\% and $48 \%$ amino acid identity between T. atroviride AGL1 and its homologues in T. asperellum and T. virens, respectively, while a $47 \%$ amino acid identity was found between T. asperellum and T. virens.

\section{Phylogenetic analysis}

A phylogenetic analysis was conducted with $T$. atroviride AGL1, together with aegerolysins identified from other sordariomycetes (Table S1) and previously characterized aegerolysins. The result showed low resolution for the lower branches in the phylogenetic tree, but with several terminal groups of taxa with high ( $\geq 70 \%$ ) bootstrap support (Fig. 1). Three examples of incongruence between the aegerolysin gene tree and the species relationships were identified; one Metarhizium anisopliae aegerolysin that clustered within a Clonostachys group, one $C$. chloroleuca aegerolysin that did not cluster with other Clonostachys aegerolysins, and one Penicillium rubens aegerolysin that clustered with Aspergilli aegerolysins (Fig. 1). All included basidiomycete aegerolysins formed a single monophyletic clade with $99 \%$ bootstrap support. AGL1 clustered together with the other two Trichoderma aegerolysins with 59\% bootstrap support (Fig. 1).

\section{Gene expression analysis}

Gene expression of agll was induced 3.2-fold $(P<0.001)$ in SMS medium supplemented with $R$. solani cell walls (RsCW) compared with the glucose control. In contrast, agll expression was downregulated to a non-detectable level when $T$. atroviride was grown under iron-limited (Fe lim) condition (Fig. 2a). The agll gene was also expressed in all other analysed culture media conditions, including liquid SMS supplemented with NAG or chitin, and conditions limited in carbon, nitrogen, and carbon + nitrogen $(\mathrm{C}$ lim,
$\mathrm{N} \lim$, and $\mathrm{C}+\mathrm{N} \lim$ ), although at the same level as the glucose control treatment. The expression of agll was not detected during fungal-fungal interactions. During asexual development, transcript abundance of agll was induced 281 -fold $(P<0.001)$ in conidiating mycelium $(\mathrm{CM})$ compared with the early stage of conidiation (ECM) (Fig. 2b). The expression of agll was not detected during vegetative growth (VM).

\section{Generation and validation of ag/1 deletion mutants}

T. atroviride agll deletion mutants were generated by replacing agll with the hygB cassette by A. tumefaciens-mediated transformation. Successful gene replacement in mitotically stable mutants was confirmed by PCR using primers located within the hygB cassette together with primers located upstream and downstream of the construct (Figure S1A) as described in our previous work (Dubey et al. 2020). The expected sizes of PCR fragments were amplified in all selected $\Delta$ agll strains, while no amplification was observed in the WT (Figure S1B). Furthermore, RT-PCR experiments using primers specific to the agll sequence demonstrated the complete loss of agll transcript in each mutant (Figure S1C).

\section{Deletion of agl1 did not affect growth rate and colony morphology}

No difference in mycelial growth rate or colony morphology was found between the WT and $\Delta a g l l$ deletion strains on PDA plates (Table S2). Although expression of agll was up-regulated in SMS medium supplemented with $\mathrm{RsCW}$, no difference in growth rate between $T$. atroviride $\mathrm{WT}$ and $\Delta$ agll strains was detected on this medium (Table S2).

\section{Deletion of $a g / 1$ results in decreased conidiation}

Conidial production of $T$. atroviride WT and $\Delta a g l 1$ strains was determined 10 dpi on PDA by counting the conidia harvested in equal amounts of water. The deletion strains showed on average a 2.9 -fold lower $(P<0.001)$ conidiation in comparison to the WT (Fig. 3).

\section{Deletion of agl1 reduces in vitro antagonism}

During in vitro dual culture interaction, no differences in growth rate of $B$. cinerea or $R$. solani were recorded during confrontation with $T$. atroviride WT compared with $\Delta$ agll strains (Table S3). Furthermore, no difference in the ability to overgrow $B$. cinerea and $R$. solani was observed between the WT and the deletion strains (data not shown). Since expression of agll was highly induced in conidiating mycelia, $B$. cinerea and $R$. solani were grown on agar plates previously colonized by conidiating mycelia of $T$. atroviride 


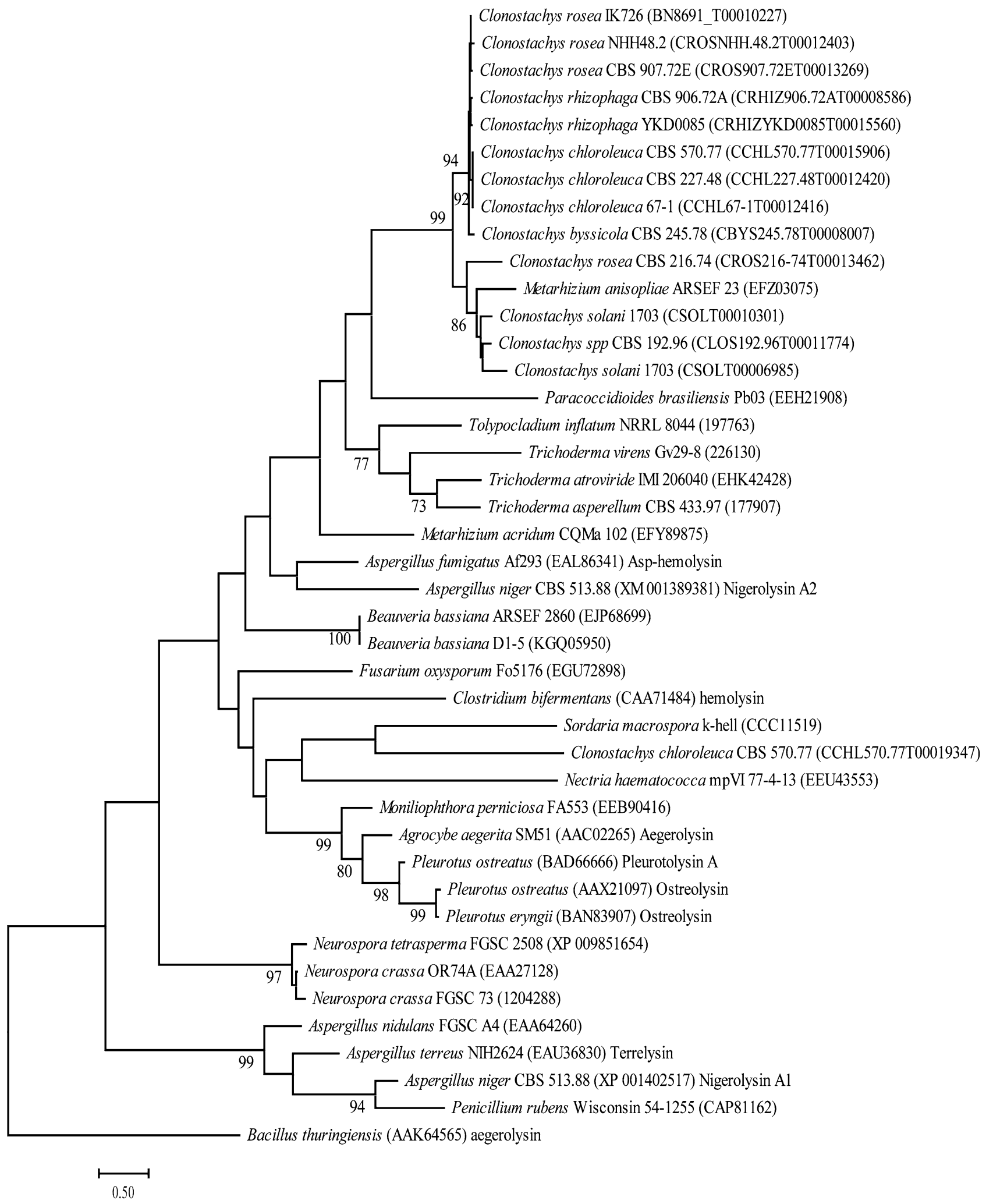

Fig. 1 Phylogenetic analysis of fungal aegerolysins. Predicted amino acid sequences of fungal aegerolysins were aligned by muscle and used to construct a phylogenetic tree using maximum-likelihood methods in MEGA X ver. 10. Branch support values (bootstrap pro- portions $\geq 70 \%$ ) are associated with nodes. Branch lengths indicate the average number of substitutions per site. Sequence identifiers include species name, GenBank ID number, or protein ID number from the respective genome project, and protein name (if available) 


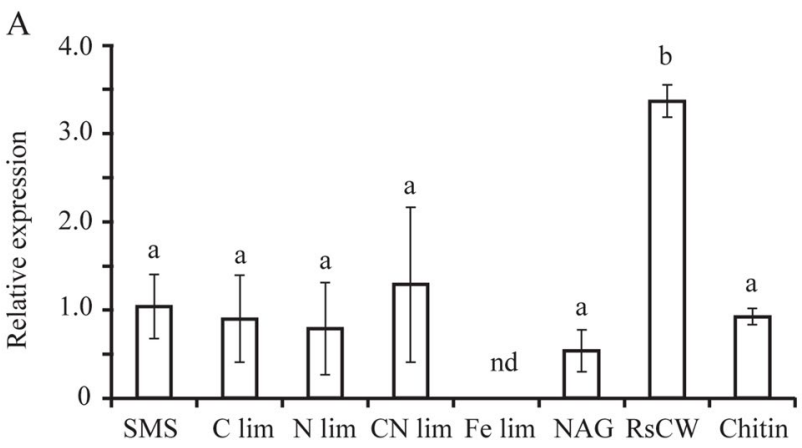

B

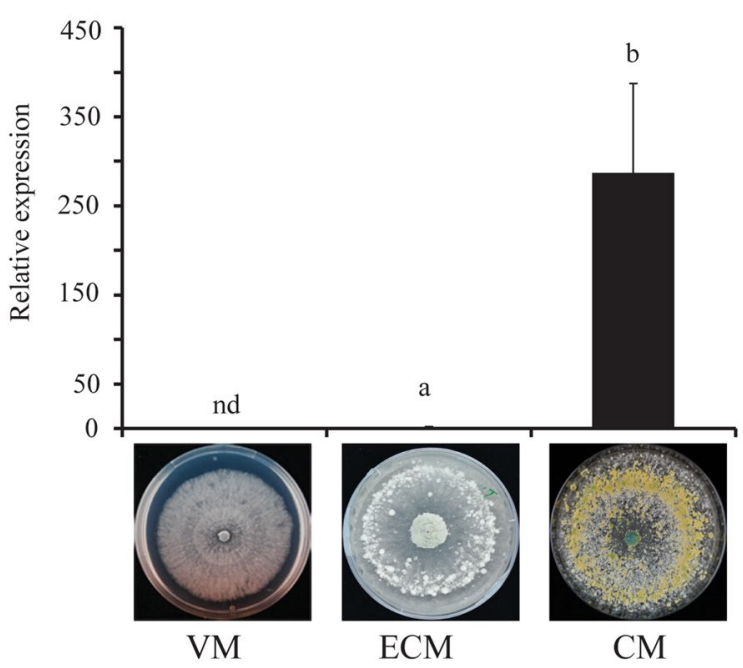

Fig. 2 Expression analyses of agll in T. atroviride. a Gene expression in mycelium grown in different nutritional/stress condition. b Gene expression analysis during different developmental stages. $V M$ vegetative mycelia, $E C M$ early stage of conidiation, $C M$ conidiated mycelia. Relative expression levels for agll in relation to actl were calculated from the $\mathrm{Ct}$ values and the primer amplification efficiencies using the formula described by Pfaffl (2001). Error bars represent standard deviation based on four biological replicates. Different letters indicate statistically significant differences $(P \leq 0.05)$ within experiments based on the Tukey-Kramer test

WT or $\Delta a g l l$ strains. Secretion assay showed significant reduction $(P=0.001)$ in growth rate of $B$. cinerea and $R$. solani on agar plates previously colonized by $T$. atroviride WT compared with control PDA plates (Fig. 4). Growth rate of $B$. cinerea and $R$. solani was $25 \%$ higher $(P \leq 0.038)$ and $87 \%$ higher $(P \leq 0.022)$, respectively, when grown on PDA plates previously colonized by $\Delta a g l l$ strains compared with T. atroviride WT (Fig. 4). However, microscopic analysis showed no difference in hyphal/mycelial morphology of $B$. cinerea and $R$. solani grown on agar plates previously colonized by conidiating mycelia of $T$. atroviride WT or $\Delta$ agll strains. Microscopic analysis indicates that the low growth rate of $B$. cinerea and $R$. solani on agar plates previously colonized by $\Delta a g l l$ strains is not connected with deformation or lysis of hyphae.
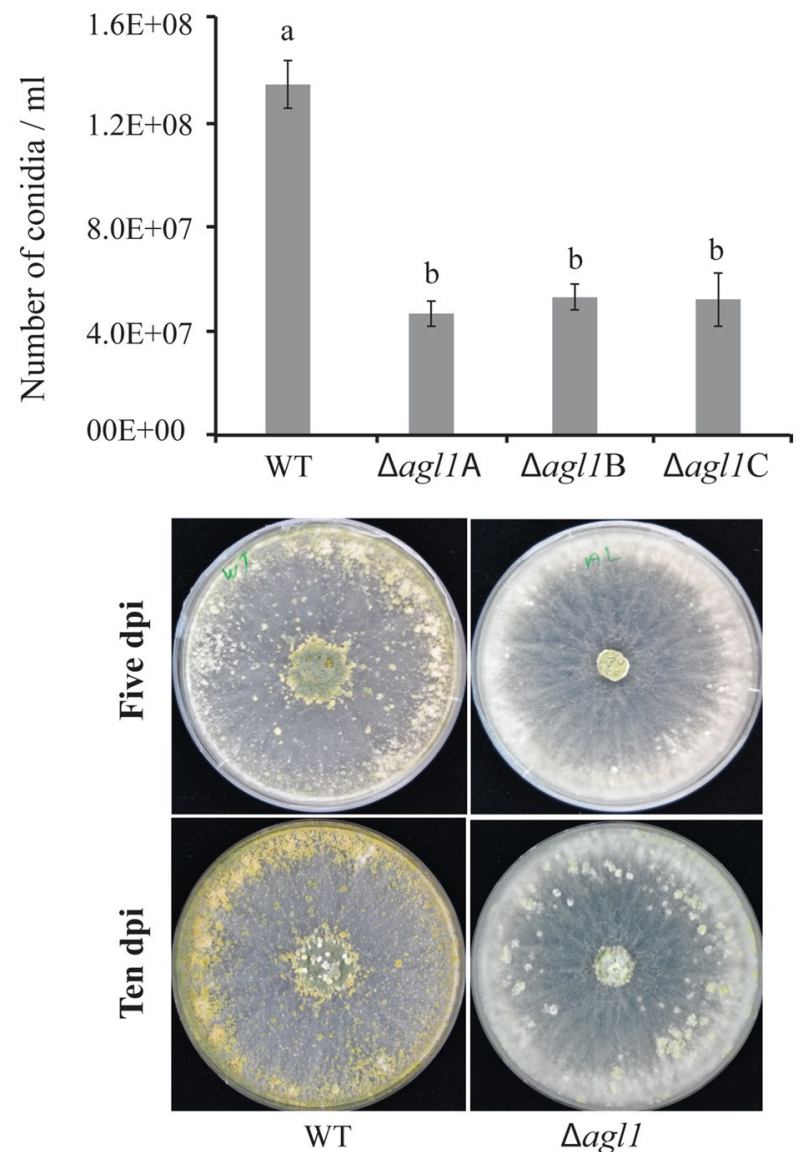

Fig. 3 Conidiation in T. atroviride WT and $\Delta a g l l$ strains on PDA medium. Conidia from the WT and deletion strains were harvested in equal volume of water and number was determined using a brightline haemocytometer as per instruction of manufacturer. Error bars represent standard deviation based on three biological replicates. Different letters indicate statistically significant differences $(P \leq 0.05)$ within experiments based on the Tukey-Kramer test

\section{Discussion}

The predicted structure of AGL1 in T. atroviride, with a single aegerolysin domain and the lack of a N-terminal secretion signal peptide, is similar to known aegerolysin proteins (Butala et al. 2017; Novak et al. 2019). We only identified aegerolysin genes in 26 out of 100 investigated sordariomycete genomes, which is in line with a previous study where putative aegerolysins was found to be present only in $22 \%$ of the fungal genomes sequenced until year 2014 (Novak et al. 2015). Taxonomic distribution of aegerolysin genes is further reported to be patchy across the fungal kingdom with low correlation to ecological niches or lifestyles (Novak et al. 2015; Butala et al. 2017), although we only identified two genera, Trichoderma and Fusarium, where the presence/ absence of aegerolysin genes between species was detected.

Phylogenetic analyses of aegerolysins reveal considerable incongruence between gene and species trees (Butala 


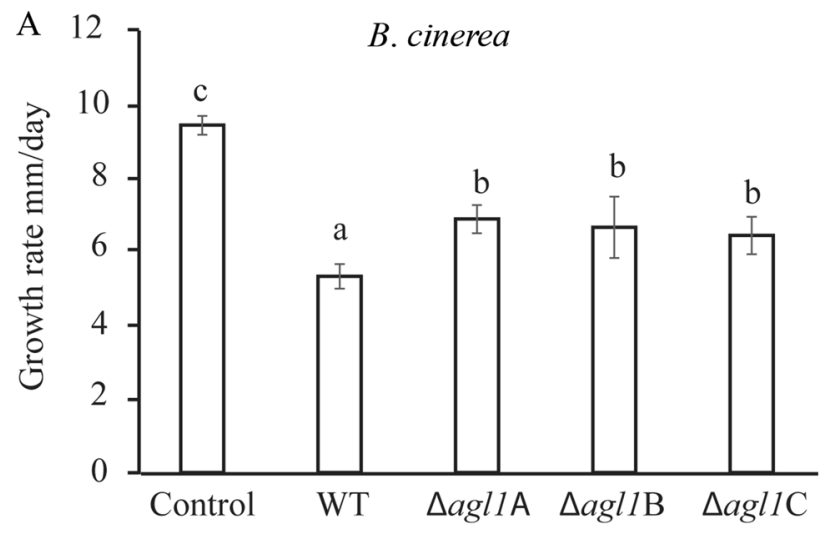

B

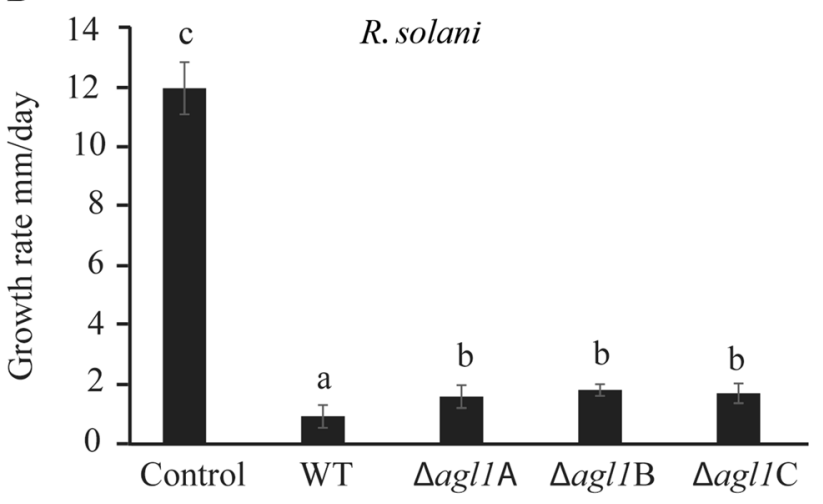

Fig. 4 Secretion assay of $T$. atroviride strains. Agar plugs were inoculated on PDA plates covered with cellophane and incubated at $25{ }^{\circ} \mathrm{C}$. After 3 dpi, the colony was removed together with the cellophane disc. Plates were re-inoculated with an a $B$. cinerea or $\mathbf{b} R$. solani agar plug, incubated at $25{ }^{\circ} \mathrm{C}$ in darkness, and the growth diameter recorded at 3 dpi. $B$. cinerea or $R$. solani agar plugs inoculated on PDA plates that were not previously inoculated with $T$. atroviride strains were used as control. Error bars represent standard deviation based on three biological replicates. Different letters indicate statistically significant differences $(P \leq 0.05)$ within experiments based on Fisher's exact test

et al. 2017), which, together with their uneven taxonomic distribution, suggests that horizontal gene transfer events contribute to the evolutionary history of aegerolysins (Moran et al. 2012). Our phylogenetic analysis is in line with this hypothesis, as we detected three cases with incongruencies between gene and species tree that are difficult to explain with lineage-specific gene losses. Similar patterns of taxonomic distribution and phylogenetic clustering are reported for two other pore-forming proteins, aerolysins and actinoporins (Szczesny et al. 2011; Moran et al. 2012). Although the amino acid sequence identities between the identified Trichoderma aegerolysins are low, as reported for other aegerolysins (Moran et al. 2012; Butala et al. 2017), they cluster together in a monophyletic group in the phylogenetic analysis.
Certain fungal aegerolysins are suggested to be involved in sexual development and fungal virulence (Novak et al. 2015; Butala et al. 2017). We therefore tested the involvement of T. atroviride AGL1 in these functions by investigating regulatory patterns and by generating agll deletion strains. The high expression of agll in conidiating mycelia indicates a role for AGL1 in conidial development. This is consistent with the expression pattern of aegerolysin genes in A. niger where expression of nigAl and nigA2 is induced in conidiating mycelia (Novak et al. 2019). The role of AGL1 in conidiation is further verified by the reduced conidial production in the $\Delta a g l l$ strains compared with the $T$. atroviride WT. The reduced conidial production in $\Delta$ agll strains is in contrast to the previous findings involving $A$. niger and A. fumigatus, in which deletion of nigAl and nigA2 and aspHS resulted in mutants with no difference in conidial production (Wartenberg et al 2011; Novak et al. 2019). The exact mechanistic connection between AGL1 and asexual development in T. atroviride requires further investigation. However, we may speculate that the reduced conidiation in $\Delta a g l l$ strains is the result of disturbed interactions between the aegerolysin and a membrane lipid (Novak et al. 2019; Panevska et al. 2019). The role of membrane lipids and lipid-mediated cellular signaling in conidiation of filamentous fungi is well known (Li et al. 2007; Rhome and Del Poeta 2009; Hubar et al. 2019).

Expression of agll is abolished during hyphal growth in iron-limiting medium, suggesting that iron is a positive regulator of agll expression in T. atroviride. A similar result is reported from $A$. fumigatus where expression of the aspHS aegerolysin gene is significantly reduced during iron-limiting condition (McDonagh et al. 2008). On the other hand, the expression of nigA1 and nigA2 in A. niger is not affected under similar condition, indicating speciesspecific adaptation of aegerolysin gene regulation (Novak et al. 2019). Several putative iron-dependent dioxygenases are differentially regulated during conidial development in $T$. reesei (Metz et al. 2011), which may suggest a possible connection between agll regulation by iron and during conidial development.

Expression of agll was not detected in T. atroviride during interactions with neither $B$. cinerea nor $R$. solani, suggesting that AGL1 is dispensable for mycoparasitism. Accordingly, we were not able to detect any phenotypic defect regarding interspecific interactions in the $\Delta a g l 1$ strains. However, our results from the secretion assay suggest a role of AGL1 in antagonism, as higher growth rate of $B$. cinerea and $R$. solani was observed in growth media previously colonized by conidiated mycelia of $\Delta$ agll strains, compared with the lower growth rate on media colonized by the WT. This indicates the absence of a secreted factor with growth-inhibiting property in the $\Delta a g l l$ strains. This secreted factor can be AGL1 itself, 
or another factor whose expression is indirectly affected by the agll deletion. The antagonistic effect was more severe towards the basidiomycete $R$. solani compared to the ascomycete $B$. cinerea. This is in agreement with the previous reports where external application of a purified haemolysin, lebbeckalysin, from Albizia lebbeck seeds reduced the mycelial growth of $R$. solani, while no effect in mycelial growth of $F$. oxysporum, Helminthosporium maydis, Valsa mali, or Mycosphaerella arachidicola was found (Lam and Ng 2011). Similar selective effects on insects are reported for aegerolysins from $P$. ostreatus where feeding of leaf discs treated with OlyA, PlyA2, and EryA demonstrated their interaction with pleurotolysin $\mathrm{B}$ (PlyB), resulting in selective toxicity towards certain insect pests including western corn rootworm (Diabrotica virgifera virgifera) larvae and adults and Colorado potato beetle larvae (Leptinotarsa decemlineata), but not towards mealworm (Tenebrio molitor), spotted wing Drosophila (Drosophila suzukii), grain aphid (Sitobion avenae), or greater wax moth (Galleria mellonella) (Panevska et al. 2019). This selective insecticidal activity was attributed to the physiological differences between the species tested (Panevska et al. 2019).

Somewhat surprisingly, expression of agll was induced in $T$. atroviride during growth on cell wall material from $R$. solani, compared with growth on glucose- or chitincontaining media or during interaction with $R$. solani. As aegerolysins interact with membrane lipids (Novak et al. 2019; Panevska et al. 2019), it is possible that lipids present in the $R$. solani cell wall fraction (Kang et al. 2018) may act as an inducer of agll expression. Certain poreforming proteins are implicated in nutrient acquisition, for example hydralysin from the cnidarian Chlorohydra viridissima (Sher et al. 2008) and a pore-forming lytic protein from the hematophagous insect Triatoma infestans (Amino et al. 2002). However, the lack of difference in growth rate between WT and $\Delta a g l l$ strains on $R$. solani cell wall medium shows that AGL1 is dispensable for this phenotype.

In conclusion, we identified and characterized the agll aegerolysin gene in the mycoparasitic fungus $T$. atroviride. Our results indicate that AGL1 is involved in conidiation and antagonism.

Funding Open access funding provided by Swedish University of Agricultural Sciences. This study was funded by the Centre for Biological Control (CBC) at the Swedish University of Agricultural Sciences, and by the Swedish Research Council for Environment, Agricultural Sciences and Spatial Planning (FORMAS) (Grant Numbers 220-2014-289, 942-2015-1128, 2018-01420).

\section{Compliance with ethical standards}

Conflict of interest The authors declare that they have no conflict of interest.

Ethical approval This article does not contain any studies with human participants or animals performed by any of the authors.

Open Access This article is licensed under a Creative Commons Attribution 4.0 International License, which permits use, sharing, adaptation, distribution and reproduction in any medium or format, as long as you give appropriate credit to the original author(s) and the source, provide a link to the Creative Commons licence, and indicate if changes were made. The images or other third party material in this article are included in the article's Creative Commons licence, unless indicated otherwise in a credit line to the material. If material is not included in the article's Creative Commons licence and your intended use is not permitted by statutory regulation or exceeds the permitted use, you will need to obtain permission directly from the copyright holder. To view a copy of this licence, visit http://creativecommons.org/licenses/by/4.0/.

\section{References}

Amino R, Martins RM, Procopio J, Hirata IY, Juliano MA, Schenkman S (2002) Trialysin, a novel pore-forming protein from saliva of hematophagous insects activated by limited proteolysis. J Biol Chem 277:6207-6213

Bando H, Hisada H, Ishida H, Hata Y, Katakura Y, Kondo A (2011) Isolation of a novel promoter for efficient protein expression by Aspergillus oryzae in solid-state culture. Appl Microbiol Biotechnol 92:561-569

Bendtsen JD, Nielsen H, von Heijne G, Brunak S (2004) Improved prediction of signal peptides: SignalP 3 0. J Mol Biol 340:783-795

Berne S, Križaj I, Pohleven F, Turk T, Maček P, Sepčić K (2002) Pleurotus and Agrocybe hemolysins, new proteins hypothetically involved in fungal fruiting. Biochim Biophys Acta 1570:153-159

Bork P, Letunic I, Doerks T (2009) SMART 6: recent updates and new developments. Nucleic Acids Res 37:D229-D232

Brunner K, Omann M, Pucher ME, Delic M, Lehner SM, Domnanich P, Kratochwill K, Druzhinina I, Denk D, Zeilinger S (2008) Trichoderma $\mathrm{G}$ protein-coupled receptors: functional characterization of a cAMP receptor-like protein from Trichoderma atroviride. Curr Genet 54:283-299

Butala M, Novak M, Kraševec N, Skočaj M, Veranič P, Maček P et al (2017) Aegerolysins: lipid-binding proteins with versatile functions. Semin Cell Dev Biol 72:142-151

Druzhinina IS, Seidl-Seibot V, Herrera-Estrella A, Horwitz BA, Kenerley CM, Monte E et al (2011) Trichoderma: the genomics of opportunistic success. Nat Rev Microbiol 9:749-759

Dubey MK, Ubhayasekera W, Sandgren M, Jensen DF, Karlsson M (2012) Disruption of the Eng18B ENGase gene in the fungal biocontrol agent Trichoderma atroviride affects growth, conidiation and antagonistic ability. PLoS ONE 7:e36152

Dubey M, Vélëz H, Broberg A, Jensen DF, Karlsson M (2020) LysM proteins regulate fungal development and contribute to hyphal protection and biocontrol traits in Clonostachys rosea. Front Microbiol 11:679

Edgar RC (2004) MUSCLE: multiple sequence alignment with high accuracy and high throughput. Nucleic Acids Res 32:1792-1797

Fernandez Espinar MT, Labarère J (1997) Cloning and sequencing of the Aa-Pril gene specifically expressed during fruiting initiation 
in the edible mushroom Agrocybe aegerita, and analysis of the predicted amino-acid sequence. Curr Genet 32:420-424

Gilbert RJC, Mikelj M, Dalla Serra M, Froelich CJ, Anderluh G (2013) Effects of MACPF/CDC proteins on lipid membranes. Cell Mol Life Sci 70:2083-2098

Hernández-Oñate MA, Esquivel-Naranjo EU, Mendoza-Mendoza A, Stewart A, Herrera-Estrella AH (2012) An injury-response mechanism conserved across kingdoms determines entry of the fungus Trichoderma atroviride into development. Proc Natl Acad Sci USA 109:14918-14923

Huber A, Oemer G, Malanovic N, Lohner K, Kovács L, Salvenmoser W et al (2019) Membrane sphingolipids regulate the fitness and antifungal protein susceptibility of Neurospora crassa. Front Microbiol 10:605

Inglis GD, Kawchuk LM (2002) Comparative degradation of oomycete, ascomycete, and basidiomycete cell walls by mycoparasitic and biocontrol fungi. Can J Microbiol 48:60-70

Joh JH, Lee SH, Lee J, Kim KH, Jeong SJ, Youn WH et al (2007) Isolation of genes expressed during the developmental stages of the oyster mushroom, Pleurotus ostreatus, using expressed sequence tags. FEMS Microbiol Lett 276:19-25

Kang X, Kirui A, Muszyński A, Widanage MCD, Chen A, Azadi P, Wang T (2018) Molecular architecture of fungal cell walls revealed by solid-state NMR. Nature Commun 9:2747

Karimi M, De Meyer B, Hilson P (2005) Modular cloning in plant cells. Trends Plant Sci 10:103-105

Kumagai T, Nagata Y, Kudo Y, Fukuchi Y, Ebina K, Yokota K (1999) Cytotoxic activity and cytokine gene induction of Asp-hemolysin to murine macrophages. Jpn J Med Mycol 40:217-222

Kumagai T, Nagata T, Kudo Y, Fukuchi Y, Ebina K, Yokota K (2001) Cytotoxic activity and cytokine induction of Asp-hemolysin to vascular endothelial cells. Yakugaku Zasshi 121:271-275

Kumar S, Stecher G, Li M, Knyaz C, Tamura K (2018) MEGA X: molecular evolutionary genetics analysis across computing platforms. Mol Biol Evol 35:1547-1549

Lam SK, Ng TB (2011) First report of an anti-tumor, anti-fungal, antiyeast and anti-bacterial hemolysis from Albizia lebbeck seeds. Phytomedicine 18:601-608

Lee SH, Kim BG, Kim KJ, Lee JS, Yun DW, Hahn JH et al (2002) Comparative analysis of sequences expressed during the liquidcultured mycelia and fruit body stages of Pleurotus ostreatus. Fungal Genet Biol 35:115-134

Li S, Bao D, Yuen G, Harris SD, Calvo AM (2007) basA regulates cell wall organization and asexual/sexual sporulation ratio in Aspergillus nidulans. Genetics 176:243-253

Marchler-Bauer A, Lu S, Anderson JB, Chitsaz F, Derbyshire MK, DeWeese-Scott $C$ et al (2011) CDD: a conserved domain database for the functional annotation of proteins. Nucleic Acids Res 39:D225-D229

McDonagh A, Fedorova ND, Crabtree J, Yu Y, Kim S, Chen D et al (2008) Sub-telomere directed gene expression during initiation of invasive aspergillosis. PLoS Pathog 4:e1000154

Metz B, Seidl-Seiboth V, Haarmann T, Kopchinskiy A, Lorenz P, Seiboth B, Kubicek CP (2011) Expression of biomass-degrading enzymes is a major event during conidium development in Trichoderma reesei. Eukaryot Cell 10:1527-1535

Moran Y, Fredman D, Szczesny P, Grynberg M, Technau U (2012) Recurrent horizontal transfer of bacterial toxin genes to eukaryotes. Mol Biol Evol 29:2223-2230

Mukherjee PK, Horwitz BA, Kenerley CM (2012) Secondary metabolism in Trichoderma - a genomic perspective. Microbiology 158:35-45

Nayak AP, Blachere FM, Hettick JM, Lukomski S, Schmechel D, Beezhold DH (2011) Characterization of recombinant terrelysin, a hemolysin of Aspergillus terreus. Mycopathologia 171:23-34

Nayak AP, Green BJ, Friend S, Beezhold DH (2012) Development of monoclonal antibodies to recombinant terrelysin and characterization of expression in Aspergillus terreus. J Med Microbiol 61:489-499

Novak M, Kraševec N, Skočaj M, Maček P, Anderluh G, Sepčić K (2015) Fungal aegerolysin-like proteins: distribution, activities, and applications. Appl Microbiol Biotechnol 99:601-610

Novak M, Čepin U, Hodnik V, Narat M, Jamnik M, Kraševec N, Sepčić K, Gregor G (2019) Functional studies of aegerolysin and MACPF-like proteins in Aspergillus niger. Mol Microbiol 112:1253-1269

Nygren CMR, Eberhardt U, Karlsson M, Parrent JL, Lindahl BD et al (2008) Growth on nitrate and occurrence of nitrate reductaseencoding genes in a phylogenetically diverse range of ectomycorrhizal fungi. New Phytol 180:875-889

Ota K, Leonardi A, Mikelj M, Skočaj M, Wohlschlager T, Künzler M et al (2013) Membrane cholesterol and sphingomyelin, and ostreolysin A are obligatory for pore-formation by a MACPF/CDC-like pore-forming protein, pleurotolysin B. Biochimie 95:1855-1864

Panevska A, Hodnik V, Skočaj M, Novak M, Modic Š, Pavlic I et al (2019) Pore-forming protein complexes from Pleurotus mushrooms kill western corn rootworm and Colorado potato beetle through targeting membrane ceramide phosphoethanolamine. Sci Rep 25:5073

Pfaffl M (2001) A new mathematical model for relative quantification in real time RT-PCR. Nucleic Acids Res 29:2001-2007

Rhome R, Del Poeta M (2009) Lipid signaling in pathogenic fungi. Annu Rev Microbiol 63:119-131

Roberts WK, Selitrennikoff CP (1988) Plant and bacterial chitinases differ in antifungal activity. J Gen Microbiol 134:169-176

Roberts RG, Bischoff JF, Reymond ST (2011) Differential gene expression in Alternaria gaisen exposed to dark and light. Mycol Prog 11:373-382

Sher D, Fishman Y, Melamed-Book N, Zhang M, Zlotkin E (2008) Osmotically driven prey disintegration in the gastrovascular cavity of the green hydra by a pore-forming protein. FASEB J 22:207-214

Shibata T, Kudou M, Hoshi Y, Kudo A, Nanashima N, Miyairi K (2010) Isolation and characterization of a novel two-component hemolysin, erylysin A and B, from an edible mushroom, Pleurotus eryngii. Toxicon 56:1436-1442

Shim SM, Kim SB, Kim HY, Rho HS, Lee HS, Lee MW et al (2006) Genes expressed during fruiting body formation of Agrocybe cylindracea. Mycobiology 34:209-213

Szczesny P, Iacovache I, Muszewska A, Ginalski K, van der Goot FG, Grynberg M (2011) Extending the aerolysin family: from bacteria to vertebrates. PLoS ONE 6:e20349

Tomita T, Noguchi K, Mimuro H, Ukaji F, Ito K, Sugawara-Tomita N et al (2004) Pleurotolysin, a novel sphingomyelin-specific twocomponent cytolysin from the edible mushroom Pleurotus ostreatus, assembles into a trans-membrane pore complex. J Biol Chem 279:26975-26982

Utermark J, Karlovsky P (2008) Genetic transformation of filamentous fungi by Agrobacterium tumefaciens. Front Microbiol https://doi. org/10.1038/nprot.2008.83

Wartenberg D, Lapp K, Jacobsen ID, Dahse HM, Kniemeyer O, Heinekamp T et al (2011) Secretome analysis of Aspergillus fumigatusreveals Asp-hemolysin as a major secreted protein. Int J Med Microbiol 301:602-611

Whelan S, Goldman N (2001) A general empirical model of protein evolution derived from multiple protein families using a maximum-likelihood approach. Mol Biol Evol 18:691-699

Publisher's Note Springer Nature remains neutral with regard to jurisdictional claims in published maps and institutional affiliations. 